\title{
Human Resources Management in the Public Hospital Case of the University Hospital Centre of Oran
}

\author{
Dr. Ghrissi Larbi \\ University of Mascara -Algeria
}

\begin{abstract}
:
it would seem that the University Hospital Centre of Oran suffers from an insufficiency in the control existing human resources and of an inadequacy enters the needs and the profiles existing on the one hand, and that it would not have a true policy of management of human resources which would enable him to benefit best from the resources human available to take up the challenges of management and the development of services provided to the patients.
\end{abstract}

Keywords: Human resources management, University hospital, Public sector, Recruitment, Skills assessment, Skills training.

\section{Introduction:}

History of the personnel management is old, complex and varied. It evolved, particularly between two poles, from the 19th to the end of the 20th century, moving from an undifferentiated function to a strategic function. Two major steps marked its development during the second half of the century.

Between 1950 and 1970, signs of the function recognition and professionalization appeared, then the conquest of autonomy, and finally, the introduction of human relationships techniques. At the same time, the research of the match between the expectations of men at work and the constraints of the organizations appeared.

From the 1970s, a phase of transformation of the socio-economic data, particularly in the public sector, emerged. The transformation of values, aspirations, and claims altered the power link in the work environment, especially because of the economic and technological progress as well as the organizational and social-cultural sciences.

Within such new context, human resources' management is becoming predominant. It has progressively upgraded to a strategic function and is contributing to the control of the change management.

The public hospital is part of such evolution dynamics and constraints. The empowered human capital is a factor of production and collective mobilization through participatory management. The human resources function is involved in this new mission.

Study of the personnel function is defined through two themes. It is concerned first with, a comprehensive approach regarding the human resources' management in every sense and which addresses the review of the achievement of the best possible adaptation of staff resources to community needs. It affects, in particular, the rules governing the implementation of the best organization in a changing environment.

The other aspect of the personnel function is concerned with the administration of people. It seeks to define, for each member of the community, the most judicious application of rules that clearly organize function within it and satisfy individual and legitimate aspirations. This more customized personnel function approach requires the use and command of tools that satisfy skills, training and the assessment needs of the social body.

At the stage of our work, we hope to show that the human resources' theme is concerned with the field staff and that the difficulties encountered cannot be solely borne by the human resources function but they must be transmitted by the entire management. 
The UCH of Oran, our research topic, seems to need a great effort to be modernized and manage its human resources.Faced with this situation; the following research issue came to mind quite naturally: What are the development lines for the establishment of an efficient and adapted management of human resources within the UCH of Oran?

\section{The hypotheses of this research are based on:}

-Human resources' management in the public hospital will be used to manage employment and develop resources;

-The hospital management will be used to support the change and include requirements and expectations.

The structure of this work retains such vision. Dividing the theoretical framework in two parts allows dealing separately, but very complimentary. On the one hand, it highlights the institution, its management, evolution in a changing world, communication, motivation and satisfaction to improve working conditions and. On the other hand, itis concerned more specifically with the human resources' management in terms of the previewed management of jobs and skills, recruitment assessment and skills training.

Therefore, the main objectives that we seek to achieve through our research in the empirical framework are:

- Establish the social report of the UCH of Oran and analyze the characteristics of the current human resource structure.

-Make an analysis of the current human resources' management of the UCH of Oran and identify shortcomings and malfunctions.

-Suggest the developmental lines of a new human resources' management policy in the UCH of Oran and provide operational recommendations for its implementation.

\section{The theoretical framework}

\subsection{The employment management and resource development}

\subsubsection{The human resources' management}

The human resources' management has always been of critical importance in the professionals' career. Actually, the first hospital resources' are its human capital. Taking account of the human factor has changed considerably over time and gradually with the advances in medical sciences, techniques, and computing, the nursing staff had then to be trained.

Such management is a set of practices with the objective of mobilizing and developing human resources for greater effectiveness and efficiency in support of the strategy of an organization. To put it simply, it is divided into two major branches: on one side, the administration of human resources such as payroll, legal matters, contract, etc, which is a more vertical activity. On the other side, the development of human resources, including human resource planning, recruitment, management and skills training, etc.

\subsubsection{The human resources' management in the public hospital}

According to J.O. Arnaud and G. Barsacq, the personnel management in a hospital is perceived from two approaches.

- The legal-administrative approach, which has as a purpose the status application and the administrative action. It corresponds more to a management of grades than individuals.

- The fiscal, economic and financial approach which corresponds to a staff management while respecting the budgetary limits without any qualitative logic.

Thus, according to $\mathrm{O}$. Derenne and $\mathrm{A}$. Lucas, the human resource management can be presented in four dimensions corresponding to the official representations: rank, index, occupation, and workstation.

\section{- The administrative approach:}

The hospital employee is in a statutory and regulatory situation governed by laws and decrees containing provisions relating to public service.Today, the Public Service Act leaves some leeway for decision-makers as for the choice of people to the extent that recruitments are based on an entrance examination, profile, choice of managerial position, evaluation, grading, etc. 


\section{- The financial approach:}

This approach is concerned with the hospital staff recruitment procedures on the basis of indexes, bonuses and allowances, and also from the perspective ofcontrolling the evolution of the wage bill.Actually, the personnel costs are about $70 \%$ of the operating expenses.

\section{- The management skills approach:}

The hospital official does no longer appear as only a "rank" but the concept of "occupation" is necessary for the human resources' management. Human resources' management policies are, therefore, directed towards:

* The staff development with the generalization of appraisal interviews.

* The training plan in coherence with the expected skills.

${ }^{*}$ Recruitment, including managerial positions on the job profile base.

* The development of career paths for the personnel.

\section{- The work organization approach:}

The mission of hospitals is to provide care for patients 24 hours a day and 365 days a year.Work organization management then becomes the spearhead of the human resources' department. The role of management is to organize work over time while maintaining the quality of life at work as well as health conditions and officers safety.

Jocelyne Abraham stated in her conclusion that "Hospitals are trying to introduce human resource management practices whose purpose is rationalized in the use of their human resources. They develop responsibility, give more autonomy to health care units, introduce new evaluation systems, and raise awareness about the need for effective assessment techniques, think of differentiated pay and promotion systems. These changes do not happen smoothly.

The main reasons are threefold, on the one hand, the lack of a culture of measurement due to the historical lack of competitive pressures directly perceptible, on the other hand, a strong culture of business directed towards care quality, based on dedication, competence and teamwork, and finally, the elementary stage of managerial culture of leadership".

\subsubsection{Areas of resources Development}

\subsubsection{Jobs and skills management}

According to Christian Batal 'The jobs and skills management is a tool for the human resources' management, which is generally defined as an iterative process that allows an organization to provide timely individuals with the capacity and sufficient motivation to "be able", "know" and "want" the jobs, fulfil missions and carry out the activities that are useful to life and evolution".

This tool is a part of several perspectives:

-A quantitative and qualitative perspective.

-An individual and collective perspective.

-A financial perspective.

Among the concepts related to Employment and Skills Planning Program in the public sector, we find the notion of competence, occupation, employment, function, the workstation and the concept of rank.

This tool is also a clear approach where we can find four major phases:

- Study of the current needs and available resources.

- Projection of the future needs and the necessary resources to fulfil them.

- Analysis of gaps to fill in order to adapt the current resources to future needs.

- The application of a policy implementation based on conventional supports of the human resources manager. 
This tool also is part of a strategic plan for recruitment, internal mobility management, requalification plans to ensure the internal modification of the competencies and professional promotions.

\subsubsection{Recruitment}

To save and improve its quality level, the hospital must maintain a selection process when recruiting. Indeed, the personnel's skills are a vital asset to the hospital so it can develop a quality approach, and according to Cremadez: "The hospital is an organization whose efficiency is mainly based on the skills of professionals that comprise it".

Recruitment includes a set of successive operations that occur in a specific order so as not to omit or over value a phase.

- The origin of need.

- Application.

- Selection.

- Reception.

- Supervision and evaluation.

- Training and granting of tenure.

\subsubsection{Skills assessment}

The evaluation concept is gaining more and more importance in the modern organizations which aim to be effective and efficient. But beyond a mere fad, evaluation is an integral part of everyday life: "Assessing is the question of meaning".

We mean the right meaning. According to Piveteau: "This is to indicate the meaning. Meaning is never given, it is always to build and rebuild. In an unstable, unpredictable and uncertain universe, a man of an organization can only live of meaning".

According to Hervé Leteurtre, assessment is part of an iterative and retroactive approach. Such assessment is based on "the appraisal of the work of an officer whose duties were defined in relation to the objectives of the hospital have been met in a procedural, environmental and human context that is imposed on him, and which effects were measured according to indicators previously identified and known to him".

For the author, the assessment is viewed as a process:

- Based on criteria, providing a basis for the assessment, behavioral criteria, autonomy...

- Which is jointly developed: for him, there are interrelations between decision-makers and implementers, as evaluators and evaluated.

- Which measures behavior: any professional act reflects social behavior signing a result.

By comparing and analyzing the results of the agent from year to year, the assessment contributes to an improvement in practice.

According to Jacques Piveteau, assessment should not limit itself to the notion of the result. "It must be understood as a regulatory mechanism between two people, a mutual adjustment process, and an assessment whose main value is that it remains qualitative".

With the annual assessment procedure, Hadji wonders about the meaning given to assessment: "Assessing not a professional, but a person is seeking and building, without that such construction could ever be considered complete, the suitable referent to allow capturing this person in his irreducible singularity. There will be assessed only when the qualitative emerges in the quantitative".

Assessment is based on the approach of skills of an assistant during the annual evaluation interview with the manager. Its aim, with the use of any tools, is to arrive at a consistent conclusion on the overall results obtained from the assistant, in 
relation to criteria defined and expected by the company. Competence is defined through three levels; the assessment will follow this schedule and will include three areas of exploration:

- Assessment in terms of resources: knowledge and skills (theoretical or practical).

- Assessment at the level of results: performance.

- Assessment at the level of potential, capacity to act «the proper skills".

\subsubsection{Skills training}

Training accompanies us throughout our lives to understand knowledge. Four main steps make the organization and management of training in an institution. These steps, which are accompanied within a specific cycle and reproduced every year are:

-Detection of needs;

- Development of the training plan;

-Implementing the plan and monitoring the initiated actions;

-Finally, assessment of the results on one hand, and on the other hand, the adopted measures and methodologies.

\subsection{Evolution of the organization and change management}

\subsubsection{Organization and management in the hospital}

Henri Mintzberg's work "The structuring of organizations «reviews in a reliable manner the specifics of the hospitals' organization in the chapter on "Professional bureaucracy". His full description of the organization as a "structural configuration"admits to developing specific aspects of the hospital organization. It is defined as:

-A strategic top represented in the hospital bythe management group.

-An operating core that gathers those responsible for carrying out the essentialtasksof the organization (care units, doctors, and the nursing staff).

-A hierarchical level, the mediator between the top and bottom. It is represented by the supervisory staff.

-Functional managements devoted in particular to the organization's economic dimension.

-Logistics: I. e. cooking, laundry, transportation. These services reduce the operating core's tasks, which are considered secondary in relation to the fundamental mission of the institution allowing it to better focus there on.

The hospital organization field highlights the following features:

-A fundamental role of the operating core, in a manner different from the core units that are relatively independent of each other. As the evolution of diagnostic technologies and complex care have resulted in creating links between care services and diagnostics assistance services, for example, the hospital remains an organization where the level of specialization is very high.

-The position of the manager who manages all the organizational confusions. Indeed, the latter been appointed by the Minister of Health is responsible for the hospital's management before the board of directors. Moreover, he finds his legitimacy and power in his continued ability to keep the operating core from the upheavals that can be generated by policy changes and contradictions of the regulatory authorities.

-A hierarchical levelsettled between the strategic apex and the operating core. The director has either the abilities or the skills to guide the heads of medical services. However, he finds a level of a logistics-management and a level of a nursing staff-management, in the same way as he finds a functional hierarchy between the doctors-heads of the department and the staff. 
-A highly developed logistics under the control of the functional management members. In this sector, medical and logistics being belonged to two different worlds encourage large coordination failures, which have a strong impact on the service quality.

-Formal coordination mechanisms are weak. According to M. Cremadez, the advantage is given to two other coordination mechanisms that are the mutual adaptation between individuals and qualifications rationalization. These concepts, with their limits, allow admitting the dynamics of the hospital organization.

-The mutual adaptation based on the quality of relationships between managers provides a bond through simple, informal information, and remains therefore strictly linked to the personality of the interlocutors.

-The qualifications' rationalization gives the immediate coordination using the homogenization of the individual behaviors. It is acquired through training and allows staff within the same group to know what they can expect from each other.

The somewhat static idea of the hospital operation needs to be improved by a more dynamic conception.

\section{-Differentiation}

Organizations are open systems that must remain in a dynamic equilibrium with their environment. The hospital structure, in a number of units, divides the environment into many different sub-environments. Each hospital service maintains favorable relationships with a part of the environment. R. Lawrence and J. W. Lorsch determines the phenomenon of differentiation.

This concept helps, for service, to determine the methods of work organization, individual behaviors and the types of relationships that differentiate it from other services.

This phenomenon, which occurs in several lines of an organization, is part of a dynamics. It allows adjusting the organizational characteristics to the proper sub-environment ones.

Moreover, differentiation is the origin of efficiency and every organization has to maintain a degree of differentiation of such configurations. Actually, it should not be allowed by a desire for consistency, to reduce the differences but rather seek to value them. Differentiation in most hospitals is found in many forms:

\section{- Directors/ Medical differentiation:}

Two opponent worlds, it opposes the professional world in services seeking especially qualitative objectives, consisting of staff and patients, to an administrative world with the objectives of quantitative and economic nature, based on the relations with the administration in a broad sense, such as authority.

\section{-Logistics/Operating core differentiation}

Logistics activities depend on the administrative world and pursue objectives of profitability or with lower cost. The operating core, made up of doctors, pursues meanwhile qualifying objectives and cost control is not their main concern.

\section{-Differentiation within the operating core}

The distinction between the medical and non-medical staff is not secondary. If the latter is less explicit in each service in relation to the needs of interaction between doctors and paramedics, linked to the needs of patients, to pathology and treatment, it is more explicit in the context of establishing the hospital's general policy. In the case of complications or uncertainties, power struggles and ideological battles may occur. Unlike the medical staff, the paramedical body is managed in a centralized and hierarchical manner.

Differentiation supports the natural barriers to communication. The more an organization will be differentiated, the more it will be difficult to make services cooperate. Actually, every service will be oriented to see the problem in terms of its knowledge of the requirements of the hospital environment. Thus, the need seems to setup discovery measures and dispute resolution. 


\section{- Integration}

According to P. R. Lawrence and J. W. Lorsch, integration is based on knowledge of the differences, which ensure harmonization's with common objectives. The cause of the required integration depends on the acuteness of differentiation.

The essential function is a hierarchy. When differentiation is low, the hierarchy, together with the formal systems such as procedures, planning and control systems, is enough to have the essential level of integration sought to be efficient. It can be insufficient when differentiation is increasing. Additional integration methods must be developed in order to make coordination easier and more adaptable by a multiplication of modes of collaboration between individuals.According to $\mathrm{M}$. Crozier and H. Serieyx "Organizations should not survive thanks to the men and women who obey, but to men and women who decide and commit".

In a world led by effectiveness and efficiency, management was, until the 1980s, more imitated into the economy and management than sociology. Currently, the sociological approach, starting from people at work and their relationships with each other, requires the leaders to bring a different vision of the organization to design as a set of real relationships between interdependent individuals.

Also, management at the hospital should be estimated by taking into account various elements of the organization:

-People At work are not only employees but also actors and have, therefore, a margin of autonomy and a form of power. To be motivated, they need to find meaning in their work.

-They progress in an exceptionally complex system, which is the hospital, with its human, economic, scientific variables, etc.

-To predict changes, run projects and innovate, it is vital for the leader to transform his image and build a strategic thinking.

Power is a concept that covers many forms and this term may designate different realities:

-Power is a function of the state: legislative, judicial, executive powers. In this context, power is exercised by the entire social body.

-Power represents the legal competence of a person and it concerns the function he performs.

-Hierarchy is associated with the command authority. Hierarchical power is an organization's quality like the army.

There are also other aspects of power, such as domination, force or influence and which will not be discussed.

\subsubsection{Change in the hospital}

According to Georges Arbuz and Denis DEBROSSE, the hospital enjoyed an uninterrupted evolution during postwar boom period from 1945 to 1975 , intensifying its renovation and developing its technical actors without really study and treat the difficulties generated from this development: methods in strikingly modern and penetrable, separation between services, hospitals looped over themselves, the progressive division of the professional teams and dismemberment of tasks due to specialization and prioritization, etc.

Such phase is old starting from the 1980 sand even from the 1990s, in the context where the hospital had henceforth to improve its practices and organization in reply to the numerous conflicts and demands of the environment. The public hospital service supports various external and internal reorganizations, whose guiding lines are looking for the best quality with lower costs, humanization and special services, definitely a matching occupation of the consumer and a general health approach:

-Seeking the best possible quality at the lowest cost.

-Humanization and customization of the hospital services.

-A coordinated management of the user and a global health approach.

Through this evolution change has become a major concern forthe hospital director and according to Denis DEBROSSE"Running a hospital today is being able to succeed in its modernization". 
Fundamentally, we cannot fail mention that individuals do not necessarily oppose resistance to change: there are people who are generally quite favorable to innovation.

Nevertheless, when reporting a change, the first position of individuals is that they generally express resistance, which is partially neutral and passive at first. Such resistance does not mean a definitive rejection, but it is justified by the fact that individuals seek to understand the current developments and cannot easily reject the forms or practices that they have primarily accepted.

According to A. BERNADOU"What is natural is resistance to change, not the opposite "since we find in humans "a defense system against the ideas, opinions and others' behaviors whose aim is the same: keep the one's psychic integrity".

Change cannot be decreed and to achieve it, it should not be unilateral.

\subsubsection{Communication and social dialogue in the hospital}

Communication is an essential activity for the life of an organization. In an organization, communication is related to the structure concerned to combine the attention of individuals and teams. We mean by formal communication network all the formal networks seeking to focus the information movements within and outside the organization.

Inside an organization, messages have a changing content and may take three main directions: downward, upward and horizontal.

According to Joel Cauden: "The internal communication plan is a consultation plan that tends to be conceived as an open prediction. It is built from an analysis and prior evolving needs to meet as well as from available means".

In absolute terms, the plan determines:

-The objectives of the program or the expected information campaigns,

-Relevant messages to be disseminated,

-Goals, causes, and routes involved,

- The planned intervention models,

-Schedule, resources and the budget to respect,

-The recommended methodology, etc.

The internal communication plan must ensure that the dissemination of the downward and upward information takes all the present and necessary channels and supports for a wider distribution of news, facts, events, knowledge, messages and other types of information that are desirable to bring to the attention of society, patients and users.

Through good communication, we can improve the social dialogue in the hospital. Therefore, we must enrich the interprofessional relationships by encouraging the membership of professionals and develop the social dialogue.

\subsubsection{Motivation and satisfaction to improve working conditions}

Employers and researchers have always been interested in motivation and satisfaction at work. Several theories consider the motivation theory as a content based on the incentives to action.

Maslow's theory invented the term "Hierarchy of needs" in 1940to define the origins of human motivation in relation to work, identifying the physiological and psychological needs.

The Alderfer's ERG Theory, which states the motivation, is to actor meet three sets of needs consisting of existence $(E)$, relatedness $(R)$ and growth $(G)$.

MCCLELLAND's common thread of research was that the desire to succeed is partly responsible for the economic growth. More specifically, its work aimed to discover whether there is a relationship between the need to succeed and the performance levels of individuals, businesses, and corporations. 
After having established the existence of such link, MCCLELLAND developed a training program to stimulate the desire for success among managers, small business, and other groups.

One of the McClelland's studies indicated that small businesses «established" to have a stronger need to succeed participated in the community life, invested more inenlarging their business and employed twice more people than subjects of a control group that had not received such training.

The process theories consider motivation from another angle. In such theories, what motivates a person in a given situation may not be appropriate for another person or another situation.

In this context, these theories focus more on orientation and the persistence of a behavior motivated by the emergence of motivation.

According to the expectations' theory or the Expectancy-Instrumentality-Valence theory developed by VROOM, the motivation as process is determined by three factors that would combine multiplicatively: expectancy, instrumentality, and violence.

According to Patrice Roussel "Satisfaction is commonly defined as a feeling of well-being. It is the "pleasure resulting from the fulfilment of what we expect, desire, or simply of a desirable thing".

In the organizational field, this concept does not raise any problem of interpretation and LOCKE studies on this topic is used as a reference.

Work satisfaction is defined by Locke as "A positive or pleasant emotional state resulting from the assessment made by a person of his work or work experience". It is thus an emotional response of the person facing his job.

\section{The empirical framework}

\subsection{Domain and tools of investigation}

To delimit our effective area of investigation, we began by drawing up a strategy for the Human Resources Management field at the University Centre Hospital of Oran (UCH).

The choice of the investigative tools is dictated by the nature of the target population, and we used three additional investigative tools:

-The social report in the service of a vision of the social system.

-The interview guide serving a qualitative analysis of the human resources' management system.

-The questionnaire which aims to complement the interview guide, to reach more people and check the findings of the interview guide.

\subsection{Presentation of results}

\subsubsection{Prospective quantitative approach}

\section{-Workforce distributions and evolution of the workforce as per corps:}

The University Centre Hospital of Oran has actually 4114 agents distributed into:

-917 represent $22 \%$ of the administrative corps.

-612 represent $15 \%$ for the medical corps.

- 1451 represent 48\%for the paramedical corps and 634 temporary agents.

\section{- Workforce distribution as per status:}

The University Centre Hospital of Oran has 3480 permanent agents and 634 temporary agents. We note that the tenured agents represent $85 \%$ of the total workforce, while the temporary agents represent $15 \%$. This is an important disparity in 
the configuration of the human resources at the University Centre, Hospital and which leads to raising questions of motivation and commitment and consequently the performance of $16 \%$ of the organization's human resources.

\section{-Workforce distribution as per gender:}

The feminization rate of the services' personnel at the University Centre Hospital of Oran represents $58 \%$ of the total workforce. The paramedical staff corps is the most feminized with a rate of $58 \%$ for the medical staff, and $54 \%$ of the administrative staff, and it represents $33 \%$.

We note the considerable importance which tends to put women in general in the specific jobs of the University Centre Hospital. This specificity, though positive is not without consequences for the functioning of the UCH in terms of absenteeism.

-Staff evolution: The UCH experienced a significant staff evolution in 2005 with209 new recruits, including 104 in the administrative corps, 10 in the medical corps 95 in the paramedical corps. As for departures, except death and mutation, retirement is the most requested.

-The structure as per age: About 2420 officers are aged between 25 and 40 years, which means that the UCH staff is young.

- Seniority Degree of the Human Resources: For the UCH of Oran, we find that the staff does not represent a very significant seniority.

\subsubsection{Training, attendance, and strikes:}

- Training: Information on this aspect at the $\mathrm{UCH}$ is scarce. Therefore, we tried to use the limited information available, which was the training plan for 2009-2010and the budget related to the training field.

- Staff attendance: This part cannot be treated because of the lack of information and the absence of the Human Resources Management System (HRMS).

- Strikes: All the strikes of the UCH of Oran staff form part of the collective action initiated by the entire staff of the public service. Since 2006, such strikes have taken a recurring character where every year in protest action was planned by the trade-union bodies of different crops.

\subsubsection{Qualitative approach}

\subsubsection{The UCH organization and missions}

At first, we tried to measure the agents' degree of knowledge about their work environment through knowledge of the mission carried out by the $\mathrm{UCH}$ and its role as a service provider for the patients' benefits and finally, the knowledge of the members of the $\mathrm{UCH}$ organs.

\section{- Knowing the organization and its mission}

*Knowing the regulations of the University Hospital organization:

Regulation (laws, ordinances, decrees, circulars, orders...) is the basis for the organization of the University Hospital. It defines, among others, mission, organization, and functions of University Hospital. This is the main point of entry into the university hospital environment.

However, we find that $60 \%$ of the interviewed staff ignores such regulations. And out of the $40 \%$ who knows about them, $65 \%$ have never read them.

\section{*Knowing the University Hospital missions}

$20 \%$ of the respondents do not know all the missions of the University Hospital. $45 \%$ believe that their knowledge is only partial. Only $35 \%$ knows the mission of the University Hospital of which the majority represents managers and practitioners. 


\section{-Knowing the members of the University Hospital bodies}

Members of the University Hospital bodies are supposed to be known by any University Hospital staff. However, the results showed that it was not the case since $60 \%$ of the staff knows only afew of them.

*The UCH strategy

Based on the principle that a poorly understood or an unknown strategy is a strategy doomed to failure, we will try to find out how things are at the $\mathrm{UCH}$.

The officials we interviewed believe they do not see clearly the strategy of their UCH and denounce the lack of communication in this regard. The results of the questionnaires confirm such statement; a majority of $70 \%$ of the staff questioned ignores the objectives set by the management of the Hospital.

\subsubsection{2: The management style at the $\mathrm{UCH}$}

We will try here in after to shed light on the prevailing management style in the UCH of Oran through the results obtained after questioning the hospital staff:

\section{-Decision- making system}

Direct discussions with some officials and $\mathrm{UCH}$ executives show that they consider integrating the decision-making system more as a constraint than a self enhancement.

The questionnaire results show that $75 \%$ of the staff questioned considers that they are not involved in preparing the decision-making, $15 \%$ are sometimes requested while only $10 \%$ feels they are part of the decision- making system.

\section{- Participating management and teamwork}

The answers of the respondents revealed that $90 \%$ believes that the style of the current management is not participative and that teamwork is almost absent; everybody is content to perform the tasks without having any dialogue or group dynamics.

\section{- Management per objectives}

The survey showed that only $3 \%$ of the respondents believe their manager's favor management per objective against $90 \%$ who thinks that such management style is totallyabsent, and $7 \%$ believe it is incomplete.

\section{- Delegation}

The respondents' answers revealed that over $80 \%$ thinks theyare evolving in an environment where delegation is practically absent.

As $20 \%$ of them believe there is a delegation of work, but it remains low and concerns only low-rewarding tasks.

\subsubsection{3: Information and communication system}

In this regard, we will try to identify and qualify the process of internal communication within the UCH. To do this, we relied on direct interviews and questionnaires.

\section{- Qualification of the communication process}

The communication between managers and their employees is considered non existent by $40 \%$ of respondents. It is weak and occasional for $46 \%$ of them, while $6 \%$ aresatisfied with the level of communication and $8 \%$, considers it good and up to it.

We had interviews with the UCH employees confirm such figures. Actually, communication, according to them, is arbitrary, not very formal and has no goal. Such communication is reduced in most cases to circular or memos. Thus, $80 \%$ of the respondents feel that informal communication is the most dominant within the $\mathrm{UCH}$. 


\section{- Access to information}

Although information is the raw material for most $\mathrm{CHU}$ services; two employees in three ( $70 \%$ of the employees surveyed) always or often find it difficult to access to it. $25 \%$ of the employees surveyed find it difficult sometimes, and only $5 \%$ feels they do not have difficulty accessing information when needed.

\subsubsection{4: Motivation policy and working conditions}

In this part, we tried through direct questions to assess both the degree of motivation of the $\mathrm{UCH}$ agents and working conditions.

The first question is whether the agent feels motivated to carry out his work. The answers provide a relatively negative assessmentsince $75 \%$ of the respondents feel they are not motivated. $20 \%$ are moderately motivated and only $5 \%$ feel motivated.

The second issue deals with working conditions and all employees feel that working conditions in the UCH are very unfavorable.

\subsubsection{5: Policy of the Human Resources Management}

The policy of the human resources management in force at the UCH of Oran will be approached through four lines, namely:

- Recruitment policy.

- The provisional management policy of jobs and skills.

- Skills assessment policy.

- Training policy.

\section{-Recruitment}

In the survey, we will try to identify the different facets of this process in particular through the effective recruitment method, the match between the target position and the recruited profile and definition of the workplace.

As for the recruitment process, it appears that every third employee was hired at the $\mathrm{UCH}$ through a recruitment method that goes beyond the standard competition framework.

In terms of the match of the target position with the recruited profile, the survey results show a rate of $30 \%$ dissatisfied about the adequacy position/profile (administrative body); such rate is deemed to be very high.

The lack of a clear definition of positions is likely to further aggravate the situation. A majority of $40 \%$ of the respondent's claim that the posts they occupy are not clarified.

- The provisional management of jobs

Most of the interrogated employees confirm that there is no provisional management, but an annual plan for human resources' management.

- Skills assessment $100 \%$ of the respondents confirms that the responsibility of rating falls within the management's competence. They all severely condemn the administrative procedure for assessment. They judge the system «rigid, archaic, scholastic and whose criteria are obsolete".

\section{-Training policy}

Regarding the participation of the agents in identifying the training needs, $90 \%$ of the staff surveyed state that they are not consulted during the design of training plans and that their real needs and expectations are not taken into account in the design of training plans. Only a very small minority affirms to be involved in the definition of training plans.As for the training needs, the large majority of the UCH employees are not satisfied. 


\subsubsection{6: The Human Resources function}

The HR function is the focus of the human resources management. The aim in this part of the survey is to highlight the reality of the human resources function within the $\mathrm{UCH}$ of Oran. For this, we will approach the function in two ways:

- The internal axis: where we will focus on its hierarchical positioning, its organization, its services, the means available and its own motivation system, etc.

- The external axis: where we will approach the function through the perception of the employees as internal customers about their human resources function.

- Internal diagnosis of the human resources function

\section{*Structure and means allocated to the human resources function}

For the human means of the human resources management, interviews with the employees of these departments how that they have never received training on the concepts and human resource management techniques. They learned in the field.

Regarding means and tools, we found that the management does not have the necessary means and tools to perform the duties of the human resources function properly. For working conditions, the critique that often comes up during interviews is that related to working conditions, which are considered unsuitable.

\section{*Position of the HR function in the management system of the UCH of Oran}

Apart from many hierarchical considerations, the human resources function plays a single operational role; it is still in the stage of the personnel administration. We also note that even the administrative role of the function remains hampered by a cumbersome legacy and difficult to manage.

The mission of the human resources function is not formally recorded and is not perfectly in tune with the standards of human resource management.Such situation is caused by the low priority given to such a function on the one hand, and on the other hand, the lack of openness of the said function, successful elsewhere, and which became the standard for the human resources management.

\section{* Assessment of the policies carried out by human resources management}

In principle, the human resources function carries out a set of human resources policies in coherence with the strategy and the general policy of an organization.

The diagnosis of the human resources function within the $\mathrm{UCH}$ shows that no human resources policy is neither defined a priori implemented. Thus, recruitment, provisional management of jobs and skills, skills assessment and training skills are processes and managerial levers that are completely absent from the scope of action of the human resources function.

\section{- External view of the human resources function}

Secondly, we will approach the human resource management function through the perception of the employees of the $\mathrm{UCH}$. For this, we used questionnaires and the results are as follows:

\section{* Efficiency of the service provided by the human resources function}

The performance of a service relates to the means allocated.Accordingto $70 \%$ of the respondents, the HR function providers are characterized by certain slow, $20 \%$ believe that the performance in terms of time is average, while $10 \%$ finds the services efficiently.

\section{${ }^{*}$ The culture service of the HR function}

At the UCH of Oran, $10 \%$ of the respondents believe that their human resources management is absolutely in a client/provider configuration, $20 \%$ also believes it, but find that this relationship feeble and must evolve and develop further. $50 \%$ do not identify with the customer / supplier relationship with respect to their human resources management and $20 \%$ did not make any statement. 


\subsection{Recommendations}

Our recommendations were made by taking into account both the legal and institutional framework of hospitals in Algeria. They were dictated by the reality of the human resources management and adjusted to address the aforementioned deficiencies based in particular on the main lines, which emerged during our analysis. We made such recommendations around areas of improvement.

-The first line is about upgrading the function of the human resource management to normalize its operations, fulfil its basic missions, and consequently support the change desired by the management.

-The second line recommends the provisional management of jobs and skills which are absent at the public health institutions. Such lack of interest, probably due to the lack of result, is mainly explained by the excessive exploitation and lack of pragmatism in the methods used.

-The third line recommends hiring, which is a major managerial act. It represents a significant investment for the institution. That is why the introduction of a recruitment procedure must strive to coordinate the actions of the professionals concerned, allow choosing the best candidates and adapt their skills to the institution's needs.

-The fourth line recommends skills' assessment. Implementation of such skills assessment system contributes to greater objectivity, transparency, participation and accountability of all actors. Professionalization and commitment of all require a real force of conviction and time.Once the plan is integrated, we witness a management operation where the win-win agreement is undeniable.

-The fifth line recommends the organization of the $\mathrm{UCH}$. The expected reform must bring new management rules, new procedures which are in line with the universal rules of management and modern management rules which consist of providing effective care, rational, efficient and economically acceptable costs, competition and bearable by the financial capacity of the country.

- The sixth line recommends management. Actually, a University Hospital Centre manager should promote a participative managerial management in a clear ethical and communicable vision. He should arouse commitment and create energies so that the participation of stakeholders in the continuous improvement of the organization becomes a reality. It is the central value of management focused on the quality of service provided to people.

In order to achieve this, the manager has no choice but, firstly, focus action on the objectives of the institution and, secondly, be clear and rigorous regarding the notion of power and delegation, the functions and the place of each person, services delivered to users and their rights and duties.

-The seventh line recommends motivation. The University Hospital Centre faces many changes concerning the financing mode, management, and quality assessment mode. All within a general context in which the social demands are increasing.

Such mutations of the hospital environment have a strong impact on the working conditions, work characteristics and the professional environment at the hospital.

In such an environment; what about work motivation of the human resources of our public hospitals? This question is becoming increasingly prominent because of the connection between staff motivation at work and the quality of patients nursing. Therefore, it is crucial, in human resources management logic, to know the motivating factors at work in order to ameliorate them.

If the Algerian public hospital wants to best fulfil its public service mission to provide quality care, the work motivation issue of its human resources must be subject to special attention by the local managers and main leaders.

-The eighth line recommends an appropriate, reliable, accurate and fast communication system. If such criteria are met, the institution may obtain three major advantages:

*Dissemination of relevant information, which enables everyone to understand the institution, to constantly adapt to hazards, to be independent and effective at work;

*Exchange, mutual enrichment, coordination and interaction between people and services; 
* Joining an ambition, values, common projects and the solidarity of all.

If communication is often experienced as a necessary evil, it is also because the human resources management is a major challenge in organizations. Actually, people are emotional and reasonable and we cannot predict which of these two aspects will be mobilized in a situation. Reactions and behaviors have an element of unpredictability.

Showing willingness to communication is the starting point of measures, which should be structured in any point of an organization. The tools and techniques are means in the service of a policy. Without such policy, they are likely to be sediment at the whim of the communication tools, trends, and developments, and quickly become more opacity symbols than elements of transparency in the eyes of employees.

An essential task of management will then be to ensure that the global approach to problems is most often present. The relationship mode dominantly observed being often reactive to the environment.

All such reactions may be effectively controlled by the internal communication. E. DUPUYand I. RAYNAUD distinguishes, for example, twelve communication principles that may encourage the staff's empowerment and commitment:

-Lucidity: It involves understanding the internal communication contingency.

-The real will: It results in the formalization of the communication function and budget allocation.

-Transparency: It opposes to the penchant for secrecy.

-Simplicity: It allows sticking to the message comprehension.

- Rapidity: It allows sticking to the event.

-Duration: It ensures that communication is a durable and progressive process.

-Tenacity: It aims to strengthen the message's significance.

- Communication development: It must be viewed as a heavy investment.

-Adaptation: It means that the internal communication is based on a corporate culture and cannot be reduced to a sort of imported gadgets.

-Adaptation: It states that communication is not neutral and that it transmits intentions.

- Anticipation: It states that communication also forms part of a future that must be identified even if it takes uncertain outlines.

Most of our recommendations involve a change, in particular practices, which is a difficult goal to achieve. Nevertheless, "Without denying the importance of the difficulties to be resolved, there are real opportunities for the development of the hospital system if the only one takes the trouble to understand the components, implement the appropriate methods and gets involved in a management style of a new kind" (Arbuz and Debrosse).

Faced with the many "recipes" that claim to deliver a «turnkey" solution for conducting and managing change, our aim is much more modest.It will not be a truth, but simply a collection of proposals based on the analysis of the specific situation of the $\mathrm{UCH}$ of Oran.

\section{Conclusion}

The survey we conducted at this establishment leadsusto think, as some theories assume, that the appropriation of change by the staff is fundamental to evolve the practices of the hospital workers in a healthy environment, which is in constant motion.

Therefore, change management cannot be seen as a function of design, command and control, but should seek to create favorable conditions for the appropriation of change, participation of individuals, investment of the close, executives, human support through training and communication, structural support for the institutionalization of change and making the environment adequately. 
In the absence of the staff's empowerment and the long process of support, simple diffusion of practice guidelines is not enough to secure the adoption of new practices.

We are aware that our conclusions may be polemical, to the extent that they amount to consider in a sense that the manager has to share power and pay more attention to personal contributions.

However, it seems on one part that it is not a question of a "sacrilege" because power is not an end in itself and, on the other part that this approach is useful and necessary for that the hospital continues to meet best the requirements constantly evolving of the population and environment.More than ever, the manager has an exemplary role. He can promote the development of the professional practices without revising his own management methods.

This research is certainly not free from limitations both in terms of theory, methodology, and of the formulation of conclusions. However, one of the limitations of this work is the one related to the limits of our research.Indeed, the extent of the human resources' management team made us reform the main objectives of our research every time and progressively.

There was another limit relating to our field of investigation portfolio. Actually, we could not reach some of our research target entities, including the Department of Health and Hospital Reform. In addition, the last limit was relating to the lack of researches in management and human resources' management in health institutions in Algeria.

\section{References:}

[1] ABBAD. J, Organisation et management hospitalier, Berger-Levrault, Paris, 2001.

[2] AKTOUF.O, Les sciences de la gestion des ressources humaines : une analyse critique, Edition, 1986.

[3] ARNAUD.J-O et BARSACQ.G, La dynamisation des ressources humaines à l'hôpital, Paris, Gérer la santé, Edition ESF, 1989.

[4] BATAL.C, La gestion des ressources humaines dans le secteur public, tome 1, Edition Organisation, 2000.

[5] BATAL.C, La gestion des ressources humaines dans le secteur public, Tome 2, Editions d'Organisation, 2000.

[6] DERENNE.O, LUCAS.A \& coordonnateurs, le développement des ressources humaines, Rennes, ENSP, 2002.

[7] -DONIUS.B, in Manuel de gestion des ressources humaines dans la fonction publique

[8] GARY D., Human resource management, 11th edition, Prentice Hall, 2004.

[9] hospitalière, tome 2 : Le développement des ressources humaines, Edition ENSP, 2002.

[10] LETEUTRE. H, L'évaluation des performances du personnel à l'hôpital, Paris, ESF ,1991. 